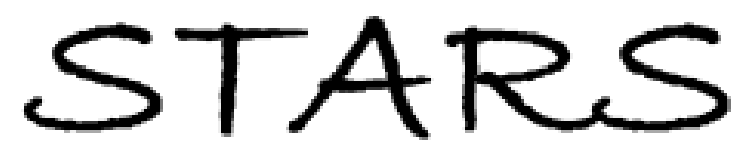

University of Central Florida

STARS

$1-1-2008$

\title{
The volatile composition of comet 17P/Holmes after its extraordinary outburst
}

\author{
N. Dello Russo \\ R. J. Vervack Jr. \\ H. A. Weaver \\ M. M. Montgomery \\ University of Central Florida \\ R. Deshpande \\ University of Central Florida
}

See next page for additional authors

Find similar works at: https://stars.library.ucf.edu/facultybib2000

University of Central Florida Libraries http://library.ucf.edu

This Article is brought to you for free and open access by the Faculty Bibliography at STARS. It has been accepted for inclusion in Faculty Bibliography 2000s by an authorized administrator of STARS. For more information, please contactSTARS@ucf.edu.

\section{Recommended Citation}

Russo, N. Dello; Vervack, R. J. Jr.; Weaver, H. A.; Montgomery, M. M.; Deshpande, R.; Fernández, Y. R.; and Martin, E. L., "The volatile composition of comet 17P/Holmes after its extraordinary outburst" (2008).

Faculty Bibliography 2000s. 268.

https://stars.library.ucf.edu/facultybib2000/268

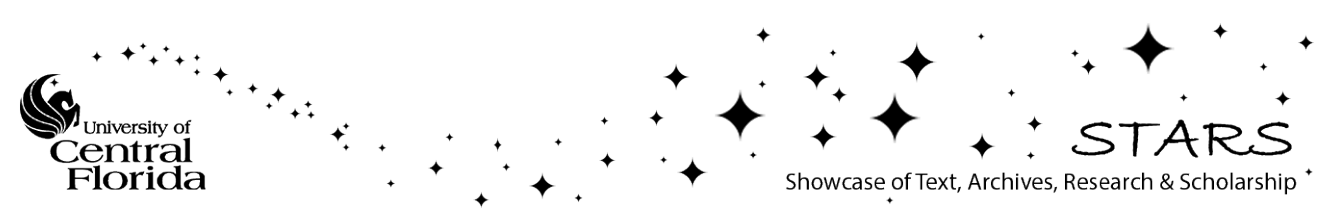




\section{Authors}

N. Dello Russo, R. J. Vervack Jr., H. A. Weaver, M. M. Montgomery, R. Deshpande, Y. R. Fernández, and E. L. Martin 


\title{
THE VOLATILE COMPOSITION OF COMET 17P/HOLMES AFTER ITS EXTRAORDINARY OUTBURST
}

\author{
N. Dello Russo, ${ }^{1}$ R. J. Vervack, JR., ${ }^{1}$ H. A. Weaver, ${ }^{1}$ M. M. Montgomery, ${ }^{2}$ \\ R. Deshrande, ${ }^{2}$ Y. R. Fernández, ${ }^{2}$ and E. L. Martin ${ }^{2,3}$ \\ Received 2007 December 14; accepted 2008 February 6
}

\begin{abstract}
The volatile abundances in comet 17P/Holmes were measured on three dates (UT 2007 October 27.6 and 31.3 and November 2.3) using high-dispersion $\left(\lambda / \Delta \lambda \sim 2.5 \times 10^{4}\right)$ infrared spectroscopy with NIRSPEC at the W. M. Keck Observatory and CSHELL at the NASA Infrared Telescope Facility. Compared to other comets, the relative gas production rates in the coma show an enhancement of $\mathrm{C}_{2} \mathrm{H}_{6}, \mathrm{HCN}$, and $\mathrm{C}_{2} \mathrm{H}_{2}$ with respect to $\mathrm{H}_{2} \mathrm{O}$, by factors of $\sim 2-3$. $\mathrm{CH}_{3} \mathrm{OH}$ was also detected with an abundance relative to $\mathrm{H}_{2} \mathrm{O}$ that is similar to or perhaps slightly enhanced compared to the values observed in other comets. The apparent enrichment of some volatiles in the coma of $17 \mathrm{P} / \mathrm{Holmes}$ does not necessarily imply an unusual composition for its nucleus because fractionation effects may be important at the relatively large heliocentric distance $\left(R_{h}=2.45 \mathrm{AU}\right)$ at which our observations were performed. Rotational temperatures were determined for $\mathrm{H}_{2} \mathrm{O}, \mathrm{HCN}, \mathrm{C}_{2} \mathrm{H}_{6}$, and $\mathrm{C}_{2} \mathrm{H}_{2}$ in the coma on UT October 27.6 and found to be between 60 and $80 \mathrm{~K}$. We used lines in both the $\nu_{5}$ and $\nu_{7}$ bands to obtain the best constraints yet achieved for the rotational temperature of $\mathrm{C}_{2} \mathrm{H}_{6}$. The spatial distributions of all measured volatiles in the coma are consistent with each other and suggest at most only a minor contribution from sublimating icy grains within our aperture. The overall gas production rate declined by approximately a factor of 7 between UT October 27.6 and November 2.3 with no significant change measured in the relative production rates of $\mathrm{C}_{2} \mathrm{H}_{6}$ and $\mathrm{H}_{2} \mathrm{O}$ during this time.
\end{abstract}

Subject headings: comets: general — comets: individual (17P/Holmes) — infrared: solar system — techniques: spectroscopic

\section{BACKGROUND}

Comet $17 \mathrm{P} /$ Holmes is a Jupiter-family comet that probably originated in the Kuiper belt based on its short period ( $6.9 \mathrm{yr}$ ), low-inclination orbit $\left(19.11^{\circ}\right)$, and Tisserand invariant with respect to Jupiter $T_{J}$ of 2.86 . In late October of 2007, this usually nondescript comet experienced an outburst extraordinary both in its timing and scale. The first reported observation of the outburst was by J. A. Henriquez Santana, who noted on UT 2007 October 24.067 that 17P had brightened to a "nuclear" magnitude of 8.4 - roughly 9 mag brighter than previously observedand that it was brightening at a rate of approximately $0.5 \mathrm{mag} \mathrm{hr}^{-1}$ (Santana 2007). Numerous follow-up observations confirmed the outburst with the reported magnitudes eventually reaching 2-3 by UT October 25-26 (Santana 2007), making 17P/Holmes a naked-eye object. Using images serendipitously obtained by the SuperWASP-N facility, Hsieh et al. (2007) noted that the comet was not visible in an image taken on UT October 23.27 (limiting magnitude of 15) but was observed in the next image taken on UT October 23.99 and steadily brightened until it saturated on UT October 24.10. Assuming a constant rate of expansion, Hsieh et al. (2007) inferred that the initial outburst occurred at approximately UT October 23.8.

The outburst of $17 \mathrm{P} /$ Holmes is exceptional for a number of reasons. First, the outburst occurred at a distance of $2.4 \mathrm{AU}$ from the Sun on the outbound leg of its orbit, about five months after perihelion ( $q=2.05 \mathrm{AU})$. Second, the outburst was enormous both in terms of increased brightness and spatial scale; the visible coma expanded rapidly and reached a radius larger than the Sun in early November. Third, a similar outburst occurred in 1892,

\footnotetext{
1 The Johns Hopkins University Applied Physics Laboratory, Laurel, MD 20723; neil.dello.russo@jhuapl.edu.

2 The Department of Physics, University of Central Florida, Orlando, FL 32816.

3 Instituto de Astrofisica de Canarias, 38200 La Laguna, Canary Islands, Spain.
}

making the comet a naked-eye object, which enabled its discovery by Edwin Holmes on UT 1892 November 6.98 and confirmation by subsequent observations (cf. Roberts 1892). Interestingly, this discovery outburst occurred about five months after perihelion and at about 2.4 AU from the Sun. Before the 2007 apparition no other significant outburst had been reported since the discovery apparition.

At present, the causes of these outbursts in $17 \mathrm{P} /$ Holmes are unknown. A grazing collision by a small companion satellite of $17 \mathrm{P}$ was proposed as the cause of the original discovery outburst (Whipple 1984, 1999). The 2007 outburst argues against this and may suggest a seasonal effect as its cause; however, any such explanation would have to account for the many apparitions where this outburst behavior was not observed. The scale of the outburst could possibly be explained by the shedding and cataclysmic disintegration of a thick layer or "talp" from the nucleus (Sekanina 2007; Thomas et al. 2007; Belton et al. 2007). Although the causes of these large outbursts are unknown, the result of the outburst on UT 2007 October 23.8 provided the opportunity to determine the chemical composition of this Jupiter-family comet. While recent studies have provided information on the parent molecule abundances in many long-period comets, Jupiter-family comets remain relatively underrepresented in molecular surveys, leaving a significant gap in our understanding of cometary composition. This study reports the composition of $17 \mathrm{P} /$ Holmes on three dates from high-resolution infrared observations obtained shortly after the initial outburst.

\section{OBSERVATIONS AND DATA ANALYSIS}

Observations were performed with the NIRSPEC spectrometer (McLean et al. 1998) at the $10 \mathrm{~m} \mathrm{W.} \mathrm{M.} \mathrm{Keck} \mathrm{Observatory} \mathrm{and} \mathrm{the}$ CSHELL spectrometer (Greene et al. 1993) at the NASA Infrared Telescope Facility on Mauna Kea, Hawaii. The observing circumstances are summarized in Table 1. At each grating setting, 
TABLE 1

Observing Circumstances

\begin{tabular}{|c|c|c|c|c|c|c|c|c|}
\hline $\begin{array}{l}\text { UT Date } \\
\text { (2007) }\end{array}$ & $\begin{array}{c}R_{h} \\
(\mathrm{AU})\end{array}$ & $\begin{array}{c}\Delta \\
(\mathrm{AU})\end{array}$ & $\begin{array}{c}\Delta_{\mathrm{dot}} \\
\left(\mathrm{km} \mathrm{s}^{-1}\right)\end{array}$ & Order/ Setting ${ }^{a}$ & $\begin{array}{c}\nu_{c}^{\mathrm{b}} \\
\left(\mathrm{cm}^{-1}\right)\end{array}$ & Volatile Targets & $\begin{array}{c}I_{\text {time }}{ }^{\mathrm{c}} \\
\text { (minutes) }\end{array}$ & Lines Used $^{\mathrm{d}}$ \\
\hline \multirow[t]{5}{*}{ 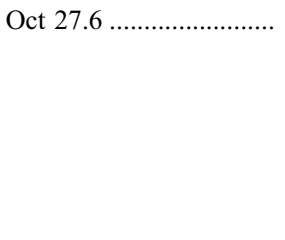 } & 2.450 & 1.629 & -2.98 & 22 & 2887.6 & $\mathrm{C}_{2} \mathrm{H}_{6}$ & 12 & 19 \\
\hline & $\ldots$ & $\ldots$ & $\ldots$ & $\ldots$ & $\ldots$ & $\mathrm{CH}_{3} \mathrm{OH}$ & $\ldots$ & 3 \\
\hline & $\ldots$ & $\ldots$ & $\ldots$ & 25 & 3279.5 & $\mathrm{HCN}$ & $\ldots$ & 8 \\
\hline & $\ldots$ & $\ldots$ & $\ldots$ & $\ldots$ & $\ldots$ & $\mathrm{C}_{2} \mathrm{H}_{2}$ & $\ldots$ & 11 \\
\hline & $\ldots$ & $\ldots$ & $\ldots$ & 26 & 3409.9 & $\mathrm{H}_{2} \mathrm{O}$ & $\ldots$ & 11 \\
\hline \multirow[t]{3}{*}{ Oct $31.3 \ldots \ldots \ldots \ldots \ldots \ldots$} & 2.464 & 1.624 & -2.21 & $\mathrm{C}_{2} \mathrm{H}_{6} \mathrm{~A}$ & 2984.5 & $\mathrm{C}_{2} \mathrm{H}_{6}$ & 32 & 2 \\
\hline & $\ldots$ & $\ldots$ & $\ldots$ & $\mathrm{H}_{2} \mathrm{OA}$ & 3514.5 & $\mathrm{H}_{2} \mathrm{O}$ & 18 & 1 \\
\hline & $\ldots$ & $\ldots$ & $\ldots$ & $\mathrm{CH}_{3} \mathrm{OHA}$ & 2842.3 & $\mathrm{CH}_{3} \mathrm{OH}$ & 24 & 1 \\
\hline \multirow[t]{2}{*}{ Nov $2.3 \ldots \ldots \ldots \ldots . .}$. & 2.472 & 1.622 & -1.45 & $\mathrm{C}_{2} \mathrm{H}_{6} \mathrm{~A}$ & 2984.5 & $\mathrm{C}_{2} \mathrm{H}_{6}$ & 36 & 2 \\
\hline & $\ldots$ & $\ldots$ & $\ldots$ & $\mathrm{H}_{2} \mathrm{OA}$ & 3514.5 & $\mathrm{H}_{2} \mathrm{O}$ & 36 & 1 \\
\hline
\end{tabular}

a NIRSPEC was used on October 27.6 and CSHELL was used on October 31.3 and November 2.3. Spectra from a single NIRSPEC setting were obtained sampling six different orders (22-27) on October 27.6, while CSHELL sampled multiple settings encompassing a much smaller wavelength range.

$\mathrm{b}$ The central wavenumber of each order or setting. Each NIRSPEC order encompasses about $40-50 \mathrm{~cm}^{-1}$, while each CSHELL setting encompasses about $7 \mathrm{~cm}^{-1}$.

c On-source integration time in minutes.

d Total number of lines used in determining the production rate and rotational temperature (when derived) for each species within an order or setting. Emissions that are a blend of more than one line are counted only once.

comet data were acquired using a sequence of four scans (source, sky, sky, source). The source and sky frames were taken in positions approximately $1 / 4$ the distance from the top and bottom of the slit, respectively (12" nod along the NIRSPEC slit; $15^{\prime \prime}$ nod along the CSHELL slit), keeping the comet within the slit during the entire scan sequence and providing sky cancellation via pixel-by-pixel subtraction. Keeping the comet "on-slit" for sky scans allowed more time on source to be obtained at the expense of spatial coverage. Flux calibrations were obtained for each grating setting and were based on observations of standard stars. The widest NIRSPEC slit is only five pixels $\left(0.74^{\prime \prime}\right)$ wide, so corrections for slit losses were included in NIRSPEC flux calibration analysis. CSHELL flux calibrations were performed with a $4^{\prime \prime}$ wide slit so no slit loss corrections were necessary.

The data were processed using algorithms specifically tailored to our comet observations. Application of these for data acquired with NIRSPEC and CSHELL have been described elsewhere (e.g., Bonev et al. 2006; DiSanti et al. 2001). Spectral frames were registered such that the spectral and spatial dimensions fell along rows and columns, respectively. Spectra were then extracted over the desired spatial extent and position along the slit (Fig. 1). Atmospheric models were obtained using the FASCOD3 transmittance model, an updated version of the original FASCOD model (Clough et al. 1981, 1988), accessing the HITRAN-2004 Molecular Data Base (Rothman et al. 2005). Atmospheric models were used to assign wavelength scales to the extracted spectra and to establish absolute column abundances for each significant absorbing species in the terrestrial atmosphere.

Volatile emission features were separated from the continuum by subtracting the normalized atmospheric model from the comet spectrum row by row, yielding the net cometary molecular emission intensities along the slit (still convolved with the atmospheric transmittance function; Figs. 1, 2). The true line flux $\left(F_{\text {line }}\right)$ incident at the top of the terrestrial atmosphere was determined within a given aperture by dividing the observed flux by the monochromatic transmittance at the Doppler-shifted line position (obtained from the fully resolved atmospheric model). Examples of line fluxes determined within 3 pixel (spectral) $\times 9$ pixel (spatial) extracts $\left(0.43^{\prime \prime} \times 1.74^{\prime \prime}\right)$ centered on the peak continuum intensity on UT October 27.6 are given in Table 2.

\section{RESULTS AND DISCUSSION}

In order to obtain the rotational temperatures and production rates from measured line fluxes, the fluorescence efficiencies $(g$ factors) for individual rovibrational lines are needed as a function of temperature. Fluorescence models for $\mathrm{H}_{2} \mathrm{O}$ hot bands have been developed based on the methodology discussed in Dello Russo et al. (2000, 2004, 2005). Developing fluorescence models for linear molecules (e.g., the $\nu_{3}$ bands of $\mathrm{HCN}$ and $\mathrm{C}_{2} \mathrm{H}_{2}$ ) is relatively straightforward (e.g., Magee-Sauer et al. 1999; Brooke et al. 1996); however, for this work we have extended the $\mathrm{C}_{2} \mathrm{H}_{2}$ fluorescence model to include the $\nu_{2}+\nu_{4}+\nu_{5}$ band. This particular band occurs in the same spectral region as the fundamental $\nu_{3}$ band and rivals it in strength, increasing by a factor of 2 the number of potentially quantifiable $\mathrm{C}_{2} \mathrm{H}_{2}$ lines in the $3 \mu \mathrm{m}$ region. This is particularly important because detecting multiple lines of $\nu_{3} \mathrm{C}_{2} \mathrm{H}_{2}$ in comets has been problematic owing to blends with other species and poor atmospheric transmittance (Dello Russo et al. 2006), while strong lines of $\nu_{2}+\nu_{4}+\nu_{5} \mathrm{C}_{2} \mathrm{H}_{2}$ generally occur in regions of higher atmospheric transmittance and less spectral confusion (Fig. 1c). Fluorescence models have been developed to quantify $\mathrm{C}_{2} \mathrm{H}_{6}$ through its strong $\nu_{7} Q$-branches in comets (Dello Russo et al. 2001). We have extended the $\mathrm{C}_{2} \mathrm{H}_{6}$ model in this work to include all $\nu_{7}$ and $\nu_{5}$ emissions, increasing the number of potentially observable $\mathrm{C}_{2} \mathrm{H}_{6}$ lines and enabling a more reliable separation of the ubiquitous $\mathrm{C}_{2} \mathrm{H}_{6}$ lines from other emitting species (particularly $\mathrm{CH}_{3} \mathrm{OH}$ ) in the $3.31-3.48 \mu \mathrm{m}$ spectral region.

\subsection{Rotational Temperatures}

The rotational temperature $\left(T_{\text {rot }}\right)$ is needed to determine total production rates from individual line intensities. We estimate $T_{\text {rot }}$ in the ground vibrational level by comparing the transmittancecorrected line fluxes $\left(F_{\text {line }}\right)$ for each species with their calculated temperature-dependent $g$-factors $\left(g_{\text {line }}\right)$ using all measured lines. At the correct rotational temperature, the quantity $F_{\text {line }} /\left(\nu_{\text {line }} g_{\text {line }}\right)$ should be independent of the average energy of the lower state of the transition (as weighted by their relative contributions to the upper state population) for all measured lines (where $\nu_{\text {line }}$ is the line frequency in $\mathrm{cm}^{-1}$ ). Additional details regarding determination 

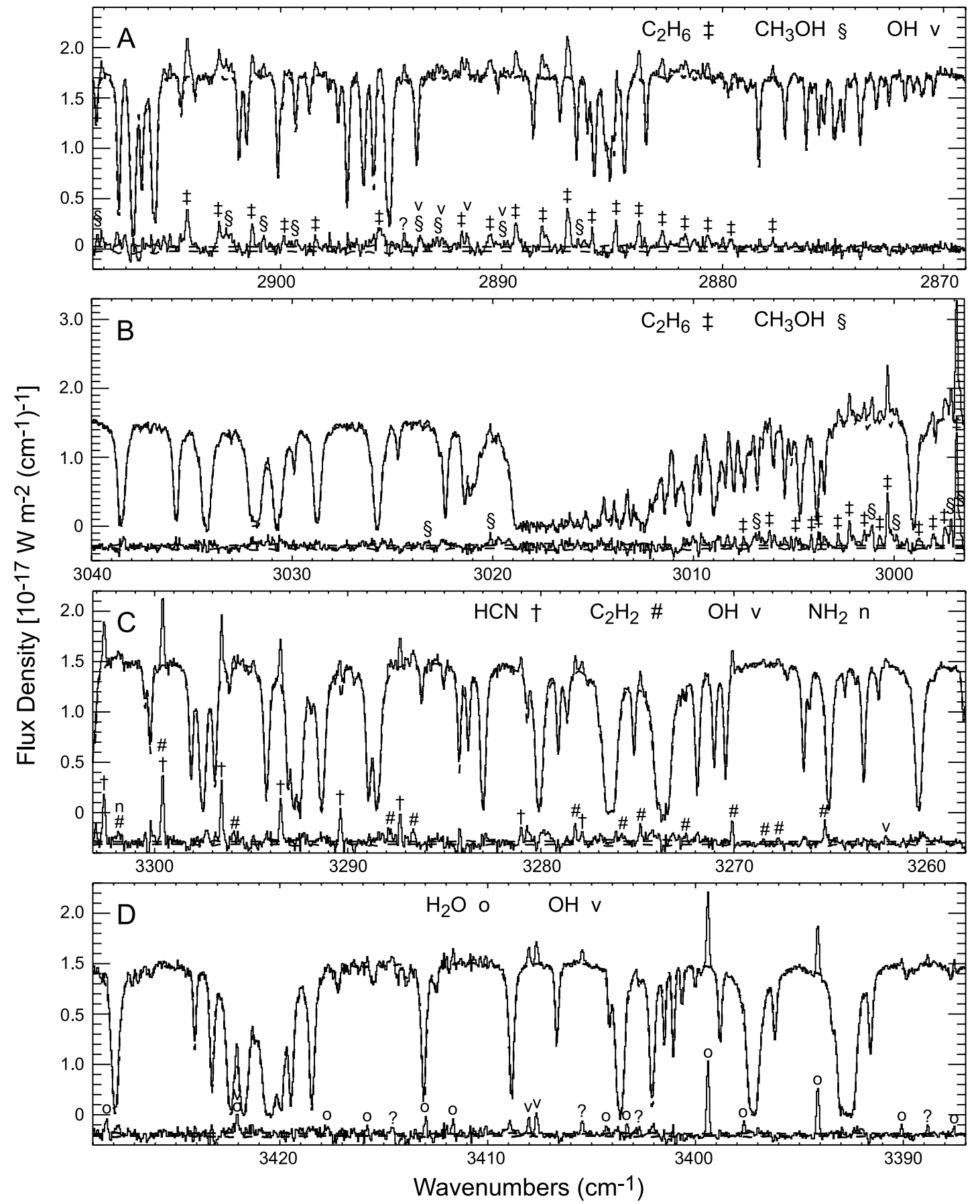

FIG. 1.-Flux-calibrated, high-resolution $(\lambda / \Delta \lambda \sim 28,000)$ spectral extracts and residuals from four NIRSPEC orders on UT 2007 October 27.6 (Table 1). Spectra are co-added over 3 spectral $\times 9$ spatial pixel extracts $\left(0.43^{\prime \prime} \times 1.74^{\prime \prime}\right)$ centered on the peak of the dust continuum. Solid traces at the top of each panel are the $17 \mathrm{P} / \mathrm{Holmes}$ spectra with the best-fit synthetic atmospheric models superimposed (dashed black lines). Molecular lines from the comet are seen as emissions in the comet spectra above the atmospheric model. Solid lines on the bottom of each panel are the continuum-subtracted spectral residuals. Emission features are noted and molecular assignments are given (some apparent spectral lines within deep atmospheric absorptions are not assigned). The dashed curves superimposed on the comet residuals are the estimated $\pm 1 \sigma$ channel-by-channel photon noise. In $(b),(c)$, and $(d)$ the comet residuals are displaced downward in flux density for clarity. $(a)$ order $22 ;(b)$ order $23 ;(c)$ order $25 ;(d)$ order 26.

of $T_{\text {rot }}$ are given in Dello Russo et al. $(2004,2005)$ and Bonev et al. (2007).

Rotational temperatures were measured for $\mathrm{H}_{2} \mathrm{O}, \mathrm{HCN}, \mathrm{C}_{2} \mathrm{H}_{6}$, and $\mathrm{C}_{2} \mathrm{H}_{2}$ on UT 2007 October 27.6 within $0.43^{\prime \prime} \times 1.74^{\prime \prime}$ apertures centered on the nucleus (which projects to $510 \mathrm{~km} \times$ $2060 \mathrm{~km}$ at the comet) and correspond to "averages" over this region of the coma (Table 3). The signal-to-noise ratio of individual lines was insufficient to meaningfully constrain $T_{\text {rot }}$ for off-nucleus extracts. On UT October 31.3 and November 2.3 an insufficient number of lines were detected to determine $T_{\text {rot }}$, so reasonable values were assumed for species detected on these dates (Table 3).

$\mathrm{H}_{2} \mathrm{O}$ rotational temperatures were determined from 14 lines in two orders (Table 1). Two additional $\mathrm{H}_{2} \mathrm{O}$ lines were detected but excluded from the analysis because their predicted intensities have been found to deviate from actual intensities observed in 


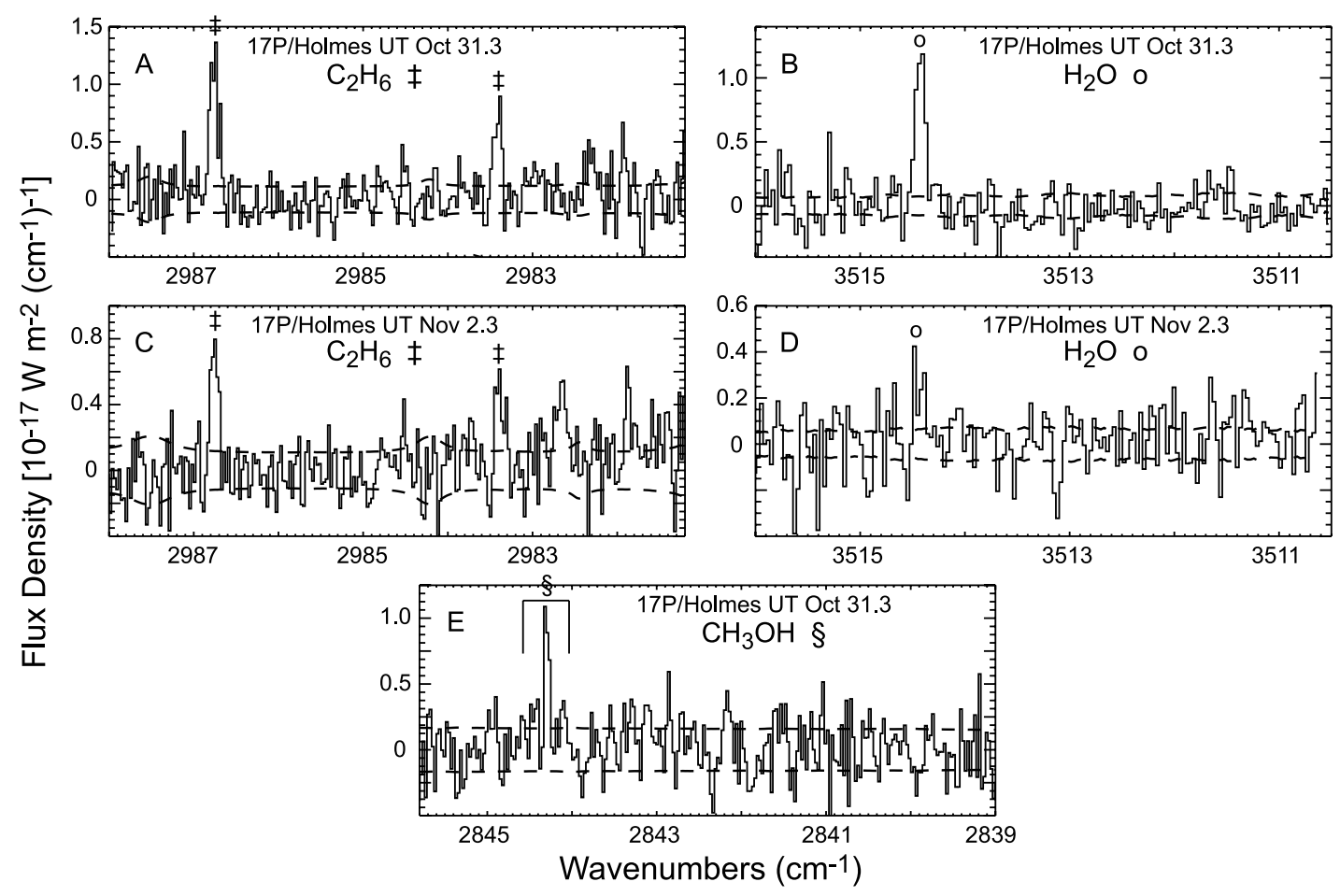

Fig. 2.-Flux-calibrated, high-resolution $(\lambda / \Delta \lambda \sim 25,000)$, continuum-subtracted spectral residuals (solid lines) from the five CSHELL grating settings sampled on UT 2007 October 31.3 and November 2.3 (Table 1). Spectra are co-added over 5 spectral $\times 5$ spatial pixel extracts $\left(1^{\prime \prime} \times 1^{\prime \prime}\right)$ centered on the peak of the dust continuum. Emission features are noted and molecular assignments are given. The dashed curves superimposed on the comet residuals are the estimated $\pm 1 \sigma$ channel-by-channel photon noise. (a) $\mathrm{C}_{2} \mathrm{H}_{6} \mathrm{~A}$ on October 31.3; (b) $\mathrm{H}_{2} \mathrm{OA}$ on October 31.3; (c) $\mathrm{C}_{2} \mathrm{H}_{6} \mathrm{~A}$ on November 2.3; (d) $\mathrm{H}_{2} \mathrm{OA}$ on November 2.3; (e) $\mathrm{CH}_{3} \mathrm{OHA}$ on October 31.3 (see Table 1 for setting identifications). The differences in line intensities between October 31.3 and November 2.3 are caused by a decrease in overall gas production rate (Table 3 ) and a significantly higher column density of atmospheric water vapor on November 2.3 (affects primarily the $\mathrm{H}_{2} \mathrm{OA}$ setting).

several comets (see Dello Russo et al. [2005] for further explanation of the criteria used for excluding lines). Inclusion of these additional lines does not change the derived rotational temperature significantly $\left(T_{\text {rot }}=71_{-7}^{+10} \mathrm{~K}\right.$ using all lines). A sufficient number of para lines (five) were detected to determine an $\mathrm{H}_{2} \mathrm{O}$ ortho-to-para ratio $(\mathrm{OPR}=2.9 \pm 0.6)$ and associated nu- clear spin temperature $\left(T_{\text {spin }}>26 \mathrm{~K}\right)$. The OPR, although poorly constrained, is consistent with the statistical equilibrium value; therefore, $\mathrm{H}_{2} \mathrm{O} g$-factors used in this analysis were calculated for $\mathrm{OPR}=3$.

$\mathrm{C}_{2} \mathrm{H}_{6}$ rotational temperatures have been determined in previously studied comets based on the relative intensities of the

TABLE 2

Sample Line FluXes in 17P/Holmes on UT October 27.6

\begin{tabular}{|c|c|c|c|c|c|}
\hline Molecule & Band Identification & Line Identification & $\begin{array}{l}\text { Line Position }{ }^{a} \\
\quad\left(\mathrm{~cm}^{-1}\right)\end{array}$ & $\begin{array}{c}g \text {-factor }{ }^{\mathrm{b}} \\
\left(10^{-7} \mathrm{~s}^{-1}\right)\end{array}$ & $\begin{array}{c}\text { Line Flux }{ }^{\mathrm{c}} \\
\left(10^{-19} \mathrm{~W} \mathrm{~m}^{-2}\right)\end{array}$ \\
\hline $\mathrm{HCN}$ & $\nu_{3}$ & P3 & 3302.546 & 265 & $8.53 \pm 0.45$ \\
\hline $\mathrm{HCN}$ & $\nu_{3}$ & $\mathrm{P} 4^{\mathrm{d}}$ & 3299.527 & 294 & $9.08 \pm 0.47^{\mathrm{d}}$ \\
\hline $\mathrm{HCN}$ & $\nu_{3}$ & P5 & 3296.488 & 288 & $9.64 \pm 0.51$ \\
\hline HCN & $\nu_{3}$ & P6 & 3293.429 & 254 & $8.01 \pm 0.44$ \\
\hline HCN & $\nu_{3}$ & P7 & 3290.349 & 205 & $6.56 \pm 0.39$ \\
\hline HCN & $\nu_{3}$ & P8 & 3287.248 & 153 & $4.36 \pm 0.26$ \\
\hline $\mathrm{HCN}$ & $\nu_{3}$ & P10 & 3280.987 & 67.2 & $2.07 \pm 0.19$ \\
\hline $\mathrm{HCN}$ & $\nu_{3}$ & P11 & 3277.826 & 39.9 & $1.72 \pm 0.18$ \\
\hline $\mathrm{H}_{2} \mathrm{O}$ & $\nu_{1}+\nu_{3}-\nu_{3}$ & $3_{13}-4_{04}$ & 3411.613 & 0.500 & $2.67 \pm 0.18$ \\
\hline $\mathrm{CH}_{3} \mathrm{OH}$ & $\nu_{2}$ & $E(0 \rightarrow-1) Q$ & 2999.85 & 20.7 & $2.30 \pm 0.23$ \\
\hline $\mathrm{C}_{2} \mathrm{H}_{6} \ldots \ldots \ldots \ldots \ldots \ldots \ldots \ldots \ldots$ & $\nu_{5}$ & $q P(3)$ & 2891.7 & 30.7 & $3.32 \pm 0.31$ \\
\hline $\mathrm{C}_{2} \mathrm{H}_{2}$ & $\nu_{3}$ & P7 & 3278.190 & 141 & $2.67 \pm 0.21$ \\
\hline
\end{tabular}

${ }^{a}$ These values are rest positions for single lines except for $\mathrm{C}_{2} \mathrm{H}_{6} \nu_{5} q P(3)$, which represents a blend of 3 lines [ $q P 0(3), q P 1$ (3), and $q P 2$ (3)].

b The $g$-factors are determined at the derived or assumed rotational temperatures on this date (see Table 3 ).

c These values are line fluxes within a 3 spectral $\times 9$ spatial pixel extract $\left(0.43^{\prime \prime} \times 1.74^{\prime \prime}\right)$ centered on the nucleus. Errors in fluxes combine photon noise (reflected in the $\mathrm{S} / \mathrm{N}$ of individual lines) and an estimated $5 \%$ error in flux calibration. Because production rates derived from nucleus-centered line fluxes are low due to slit losses, a correction factor is determined and applied to convert to an absolute production rate. The correction factors for these species were between 1.5 and 2.0 on this date.

${ }^{d}$ The $\nu_{3} P 4$ line of $\mathrm{HCN}$ is blended with the $\nu_{3} R 1$ line of $\mathrm{C}_{2} \mathrm{H}_{2}$. The listed line flux removes the contribution from the $\mathrm{C}_{2} \mathrm{H}_{2}$ line. The total line flux for the blended line is $(11.11 \pm 0.57) \times 10^{-19} \mathrm{~W} \mathrm{~m}^{-2}$. 
TABLE 3

Absolute and Relative Production Rates and Rotational TEMPERATURES IN 17P/Holmes

\begin{tabular}{cccc}
\hline \hline & $T_{\text {rot }}$ & $Q$ & \\
Molecule & $(\mathrm{K})$ & $\left(10^{27} \mathrm{~s}-1\right)$ & $Q / Q\left(\mathrm{H}_{2} \mathrm{O}\right)$ \\
\hline
\end{tabular}

UT 2007 October 27.6

\begin{tabular}{|c|c|c|c|}
\hline $\mathrm{H}_{2} \mathrm{O} \ldots \ldots \ldots$ & $73_{-7}^{+9}$ & $450 \pm 57$ & 100 \\
\hline $\mathrm{CH}_{3} \mathrm{OH}$ & $\ldots^{a}$ & $10.1 \pm 1.6$ & $2.25 \pm 0.43$ \\
\hline $\mathrm{C}_{2} \mathrm{H}_{6}$. & $79 \pm 4$ & $8.01 \pm 0.79$ & $1.78 \pm 0.26$ \\
\hline $\mathrm{HCN}$. & $65 \pm 2$ & $2.42 \pm 0.22$ & $0.538 \pm 0.075$ \\
\hline $\mathrm{C}_{2} \mathrm{H}_{2} \ldots \ldots \ldots \ldots \ldots$ & $63_{-5}^{+8}$ & $1.55 \pm 0.18$ & $0.344 \pm 0.053$ \\
\hline
\end{tabular}

UT 2007 October 31.3

\begin{tabular}{|c|c|c|c|}
\hline $\mathrm{H}_{2} \mathrm{O}$ & $60^{\mathrm{b}}$ & $175 \pm 30$ & 100 \\
\hline $\mathrm{CH}_{3} \mathrm{OH}$ &. $\mathrm{c}$ & $5.2 \pm 1.4$ & $3.0 \pm 1.0$ \\
\hline $\mathrm{C}_{2} \mathrm{H}_{6} \ldots \ldots \ldots \ldots \ldots \ldots \ldots \ldots \ldots$ & $60^{\mathrm{b}}$ & $3.32 \pm 0.76$ & $1.90 \pm 0.54$ \\
\hline
\end{tabular}

UT 2007 November 2.3

\begin{tabular}{|c|c|c|c|}
\hline $\mathrm{H}_{2} \mathrm{O}$ & $50^{\mathrm{b}}$ & $66 \pm 14$ & 100 \\
\hline $\mathrm{C}_{2} \mathrm{H}_{6} \ldots \ldots \ldots$ & $50^{\mathrm{b}}$ & $1.55 \pm 0.33$ & $2.3 \pm 0.7$ \\
\hline
\end{tabular}

${ }^{\text {a }}$ Assumes that the rotational temperature for $\mathrm{CH}_{3} \mathrm{OH}$ in $17 \mathrm{P} / \mathrm{Holmes}$ on this date is the same as in C/1999 H1 (Lee) on UT 1999 August 21. This is based on similar $\mathrm{C}_{2} \mathrm{H}_{6}, \mathrm{HCN}$, and $\mathrm{H}_{2} \mathrm{O}$ rotational temperatures in the two comets (Mumma et al. 2001a; Dello Russo et al. 2005; see text).

${ }^{\mathrm{b}}$ Assumed rotational temperatures.

${ }^{\mathrm{c}}$ Assumes a $g$-factor for the $\mathrm{CH}_{3} \mathrm{OH} \nu_{3} Q$-branch of $2.17 \times 10^{-5} \mathrm{~s}^{-1}$.

strong $\nu_{7} Q$-branches (cf. Dello Russo et al. 2001). However, relative $\mathrm{C}_{2} \mathrm{H}_{6} Q$-branch intensities are not a sensitive indicator of $T_{\text {rot }}$, because each $Q$-branch consists of many unresolved lines representing a range of energies rather than a single discrete value (Dello Russo et al. 2001). For this work, models were developed for the entire $\nu_{5}$ and $\nu_{7}$ bands, greatly increasing the potential number of $\mathrm{C}_{2} \mathrm{H}_{6}$ lines available for quantitative analysis $\left(26 \mathrm{C}_{2} \mathrm{H}_{6}\right.$ lines were used in this work; see Table 1). Although the relative intensities of $\nu_{5}$ lines are a more sensitive indicator of $T_{\text {rot }}$, they are weaker than the $\nu_{7} Q$-branches and are thus more affected by blends from the numerous $\mathrm{CH}_{3} \mathrm{OH}$ lines in this region. However, the high $\mathrm{C}_{2} \mathrm{H}_{6}$ production rate in $17 \mathrm{P} /$ Holmes (both absolute and relative to $\mathrm{CH}_{3} \mathrm{OH}$ ), coupled with the extension of these fluorescence models, allowed contributions from $\mathrm{CH}_{3} \mathrm{OH}$ and other species to be more easily isolated (Fig. 3) and enabled the most stringent constraints on the $\mathrm{C}_{2} \mathrm{H}_{6}$ rotational temperature measured in a comet to date (Table 3, Fig. 3). As a consistency check for the fluorescence model, rotational temperatures and production rates determined from $\nu_{5}$ lines were used to model the $\nu_{7}$ lines detected in a different order and line intensities were in good agreement with the model fit (Fig. 3c).

A well-constrained $\mathrm{HCN}$ rotational temperature was determined from the relative intensities of eight lines in a single order (Table 3). A rotational temperature for $\mathrm{C}_{2} \mathrm{H}_{2}$ was also derived from 11 lines in the same order. Utilizing lines from the strong $\nu_{2}+\nu_{4}+\nu_{5}$ combination band of $\mathrm{C}_{2} \mathrm{H}_{2}$ was essential for the analysis as 7 of the 11 unblended $\mathrm{C}_{2} \mathrm{H}_{2}$ lines were from the $\nu_{2}+\nu_{4}+\nu_{5}$ band, driving the need to extend the $\mathrm{C}_{2} \mathrm{H}_{2}$ fluorescence models. A comparison of the $17 \mathrm{P} /$ Holmes spectral residuals and the best-fit $\mathrm{HCN}$ and $\mathrm{C}_{2} \mathrm{H}_{2}$ fluorescence models is shown in Figure 4. Rotational temperatures derived for all four species are between about 60 and $80 \mathrm{~K}$ with $\pm 1 \sigma$ error bars in Table 3 . We note that small but significant differences (at the $95 \%$ confidence level) are seen in the derived $\mathrm{HCN}$ and $\mathrm{C}_{2} \mathrm{H}_{6}$ rotational temperatures. For a comet of this productivity, collisions are expected to thermalize the rotational population of the ground vibrational state for all (or at least a great majority) of the molecules within the aperture (projected to $510 \mathrm{~km} \times 2060 \mathrm{~km}$ at the comet) where rotational temperatures are measured (Crovisier 1987; Xie \& Mumma 1992; Bockelée-Morvan et al. 2004), so the causes of the small differences in $T_{\text {rot }}$ between $\mathrm{HCN}$ and $\mathrm{C}_{2} \mathrm{H}_{6}$ are unclear.

\subsection{Production Rates}

The methodology of generating " $Q$-curves" and using them to determine volatile production rates has been discussed in detail in previous work (Dello Russo et al. 1998, 2000; Magee-Sauer et al. 1999, 2002; DiSanti et al. 2001). These studies clearly define the "nucleus-centered" and "terminal" (off-nucleus) production rates and the relation between them. For this work, production rates were determined within nucleus-centered 3 pixel (spectral) $\times$ 9 pixel (spatial) extracts $\left(0.43^{\prime \prime} \times 1.74^{\prime \prime}\right)$ for NIRSPEC (October $27.6)$, and 5 pixel (spectral) $\times 5$ pixel (spatial) extracts $\left(1^{\prime \prime} \times 1^{\prime \prime}\right)$ for CSHELL (October 31.3 and November 2.3). Because this "raw" nucleus-centered value underestimates the true production rate (Dello Russo et al. 1998), a correction factor based on the ratio of terminal to nucleus-centered production rates was applied. To obtain this ratio, all lines of a single species within a grating setting or order are summed to generate a $Q$-curve. The ratio of terminal to nucleus-centered production rates from this $Q$-curve provides a correction factor by which the nucleuscentered $Q$ for each line within a grating setting and order can be multiplied (note that we assume a constant $T_{\text {rot }}$ from the nucleuscentered to the terminal region). This method is assumed to be valid because all lines within a single grating setting will be equally affected by seeing, drift, and telescope defocusing ( Dello Russo et al. 2005). In grating settings with many weak lines, this technique has the advantage of obtaining higher signal-to-noise ratios for line-by-line production rates (compared with using the terminal $Q$ for each line individually). Correction factors were between 1.5 and 2.0 for species measured on October 27.6 with NIRSPEC and between 2.0 and 3.0 for species measured on October 31.3 and November 2.3 with CSHELL. For this work, derived production rates are insensitive to the photodissociation lifetimes used for the species reported here (Crovisier 1994) but are directly proportional to the assumed gas outflow velocity. For this work we assume $v_{\text {gas }}=0.8 R_{h}^{-0.5} \mathrm{~km} \mathrm{~s}^{-1}$ (where $R_{h}=$ the comet heliocentric distance in $\mathrm{AU})$.

Absolute and relative production rates in 17P/Holmes are given in Table 3. The production rates on UT October 27.6 for each species are determined from a weighted average of production rates derived independently for all detected lines (the number of lines used in the analysis is given in Table 1). Errors in production rates for individual lines are based on photon noise (reflecting the signal-to-noise ratios in these lines) and an assumed $5 \%$ error in the determined $g$-factors for each line. Errors in the derived production rate for each species are not dominated by the signal-to-noise ratios of individual spectral lines (which are generally high; see Fig. 1) but by line-by-line deviations between the best-fit fluorescence model and the data. Thus, error bars in absolute production rates ( $1 \sigma$ in Table 3$)$ reflect the standard deviation from the mean of individual line measurements and the effects of small number statistics. In addition, uncertainties for the nucleus-to-terminal correction factors $(\sim 7 \%-10 \%$ as determined from the $Q$-curve) and flux calibration (5\%) were also included in absolute production rates. For relative production rates on October 27.6 (Table 3) the assumed error in flux calibration is not included because all lines were detected in a single grating/ cross-disperser setting. On UT October 31.3 and November 2.3 


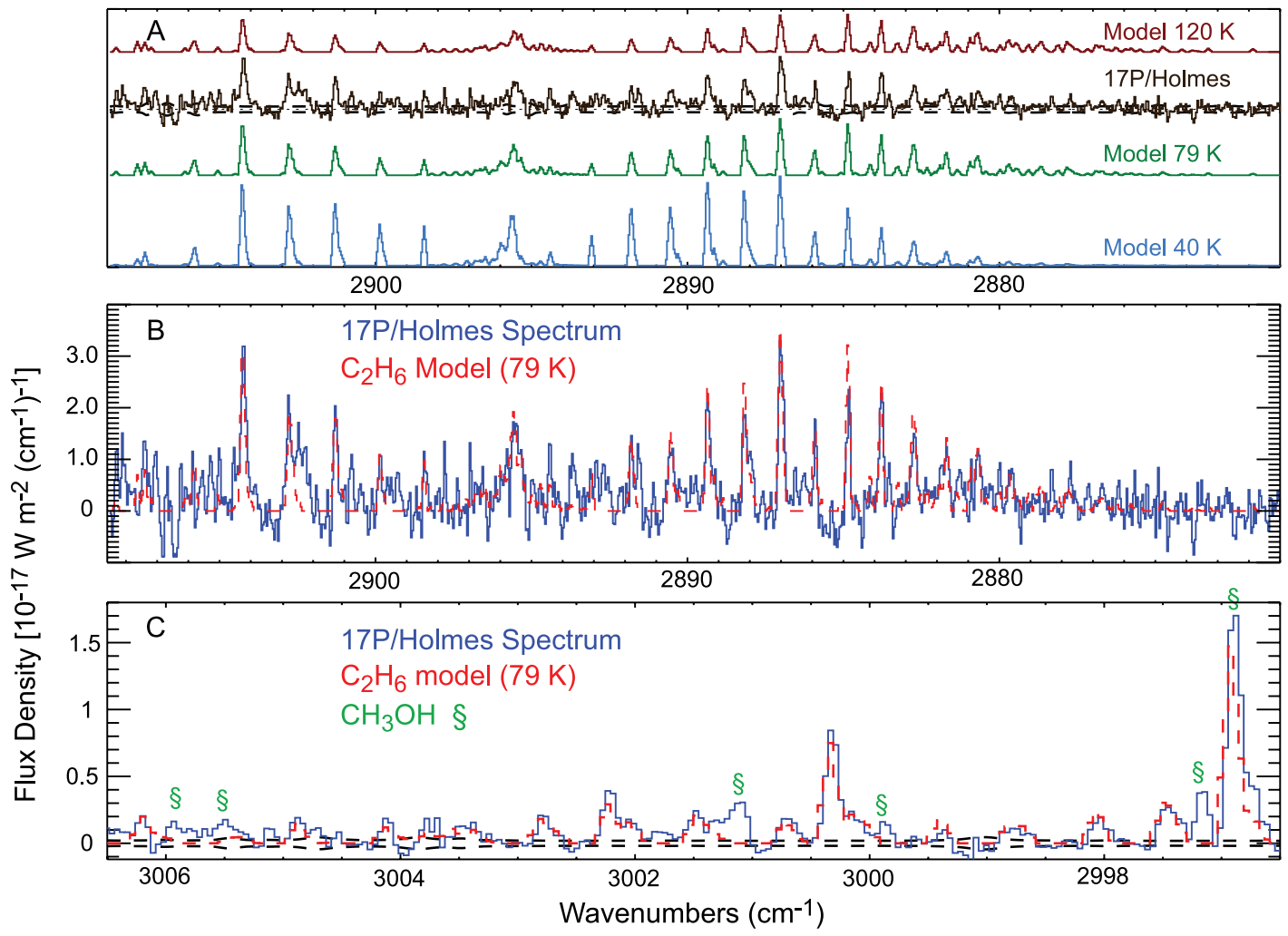

FIG. 3. - Comparison of $\mathrm{C}_{2} \mathrm{H}_{6}$ fluorescence models with 17P/Holmes spectral residuals. (a) The comparison of 17P/Holmes residuals on UT 2007 October 27.6 in NIRSPEC order 22 sampling the $\nu_{5}$ band of $\mathrm{C}_{2} \mathrm{H}_{6}$ (solid black line) with $\mathrm{C}_{2} \mathrm{H}_{6}$ fluorescence models convolved to the approximate resolution of the comet residuals at $40 \mathrm{~K}$ (solid blue line), $79 \mathrm{~K}$ (solid green line) and $120 \mathrm{~K}$ (solid brown line). The relative and absolute line intensities provide a best-fit rotational temperature of $79 \pm 4 \mathrm{~K}$ ( Table 3 ). The dashed curves superimposed on the comet residuals are the estimated $\pm 1 \sigma$ channel-by-channel photon noise. (b) 17P/Holmes spectral residuals in order 22 (solid blue line) with the $\mathrm{C}_{2} \mathrm{H}_{6}$ fluorescence model at $79 \mathrm{~K}$ superimposed (dashed red line). This reveals the contribution of $\mathrm{C}_{2} \mathrm{H}_{6}$ and excess features primarily due to $\mathrm{CH}_{3} \mathrm{OH}$ and $\mathrm{OH}_{\text {. }}$ (c) Comparison of 17P/Holmes residuals on UT 2007 October 27.6 in NIRSPEC order 23 sampling the $\nu_{7}$ band of $\mathrm{C}_{2} \mathrm{H}_{6}$ (solid blue line) to the $\mathrm{C}_{2} \mathrm{H}_{6}$ fluorescence model (dashed red line) at the production rate and rotational temperature calculated from order 22 . This demonstrates the consistency of the $\mathrm{C}_{2} \mathrm{H}_{6}$ model between the $\nu_{5}$ and $\nu_{7}$ bands and reveals contributions from $\mathrm{CH}_{3} \mathrm{OH}$ within the order. The black dashed curves superimposed on the comet residuals are the estimated $\pm 1 \sigma$ channel-by-channel photon noise.
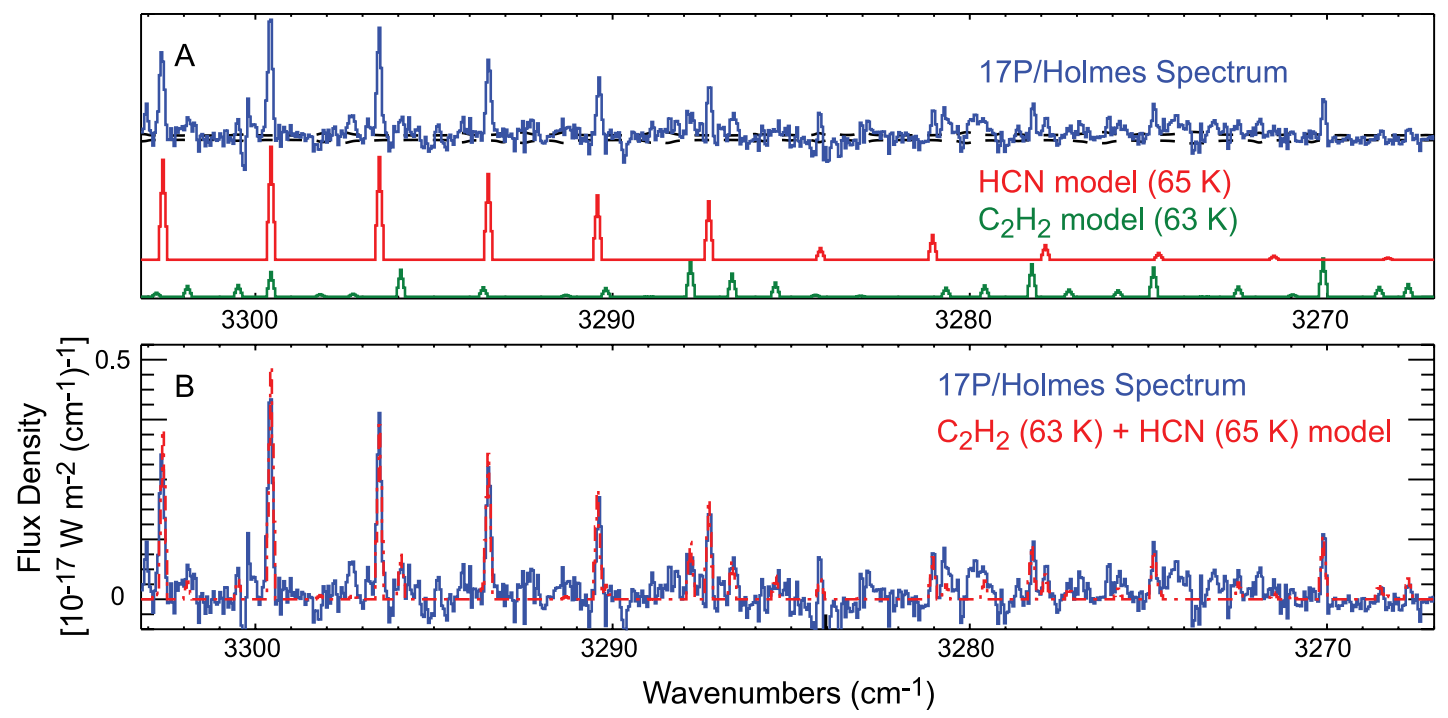

Fig. 4. - Comparison of $\mathrm{HCN}$ and $\mathrm{C}_{2} \mathrm{H}_{2}$ fluorescence models with 17P/Holmes spectral residuals. (a) Comparison of 17P/Holmes residuals on UT 2007 October 27.6 in NIRSPEC order 25 sampling the $\nu_{3}$ band of $\mathrm{HCN}$ and the $\nu_{3}$ and $\nu_{2}+\nu_{4}+\nu_{5}$ bands of $\mathrm{C}_{2} \mathrm{H}_{2}$ (solid blue line) with an $\mathrm{HCN}$ model at $65 \mathrm{~K}$ (solid red line) and a $\mathrm{C}_{2} \mathrm{H}_{2}$ model at $63 \mathrm{~K}$ (solid green line) convolved to the approximate resolution of the comet residuals. The dashed black curves superimposed on the comet residuals are the estimated $\pm 1 \sigma$ channel-by-channel photon noise. (b) $17 \mathrm{P} /$ Holmes spectral residuals in order 25 (solid blue line) with the combination of the $\mathrm{HCN}_{\text {and }} \mathrm{C}_{2} \mathrm{H}_{2}$ fluorescence models superimposed (dashed red line). 
when only one or two lines were detected for each species with CSHELL, errors in absolute production rates ( $1 \sigma$ in Table 3$)$ are based on photon noise, nucleus-to-terminal correction factor, error in individual $g$-factors of $5 \%$ plus an additional error assuming an uncertainty of $\pm 10 \mathrm{~K}$ for assumed $T_{\text {rot }}$, and flux calibration error $(5 \%)$.

The total gas production rate of $17 \mathrm{P} /$ Holmes decreased by about a factor of 7 from October 27.6 to November 2.3 as derived from the $\mathrm{H}_{2} \mathrm{O}$ production rate. $\mathrm{C}_{2} \mathrm{H}_{6}$ was the only other species measured on all three dates giving an abundance ratio of $\mathrm{C}_{2} \mathrm{H}_{6} / \mathrm{H}_{2} \mathrm{O} \sim 2 \%$, similar to that seen in comet $\mathrm{C} / 2001$ (LINEAR) A2 (Gibb et al. 2007; Magee-Sauer et al. 2008) and about 3 times that typically seen in comets. The $\mathrm{C}_{2} \mathrm{H}_{6} / \mathrm{H}_{2} \mathrm{O}$ ratio is also consistent within errors on these dates (Table 3). $\mathrm{HCN}$ and $\mathrm{C}_{2} \mathrm{H}_{2}$ were detected only on October 27.6, both with production rates enhanced relative to $\mathrm{H}_{2} \mathrm{O}$ by a factor of $\sim 2-3$ when compared to what is typically seen in comets (Bockelée-Morvan et al. 2004; Biver et al. 2002).

$\mathrm{CH}_{3} \mathrm{OH}$ was detected on two dates with an abundance ratio of $\mathrm{CH}_{3} \mathrm{OH} / \mathrm{H}_{2} \mathrm{O}$ in the typical to slightly enhanced range of that generally seen in comets (Table 3; Biver et al. 2002; BockeléeMorvan et al. 2004). Usually, $\mathrm{CH}_{3} \mathrm{OH}$ production rates determined from high-resolution near-infrared measurements are determined from the flux of the $\nu_{3} Q$-branch (cf. Mumma et al. 2001a; Dello Russo et al. 2007). However, spectra obtained on October 27.6 do not include the $\nu_{3} Q$-branch of $\mathrm{CH}_{3} \mathrm{OH}$. A production rate of $\mathrm{CH}_{3} \mathrm{OH}$ was obtained on this date first by isolating three $\mathrm{CH}_{3} \mathrm{OH}$ lines from $\nu_{7} \mathrm{C}_{2} \mathrm{H}_{6}$ emissions near $3000 \mathrm{~cm}^{-1}$ using the $\mathrm{C}_{2} \mathrm{H}_{6}$ fluorescence model (Fig. $3 c$ ). These same three $\mathrm{CH}_{3} \mathrm{OH}$ lines were detected in comet $\mathrm{C} / 1999 \mathrm{H} 1$ Lee along with the $\nu_{3} Q$ branch of $\mathrm{CH}_{3} \mathrm{OH}$, and line fluxes for these lines were reported (Dello Russo et al. 2006). The gas rotational temperatures derived in $\mathrm{C} / 1999 \mathrm{H} 1$ Lee for $\mathrm{CO}, \mathrm{C}_{2} \mathrm{H}_{6}, \mathrm{HCN}$, and $\mathrm{H}_{2} \mathrm{O}$ on UT 1999 August 21.6 were between about 70 and $80 \mathrm{~K}$ (Mumma et al. 2001a; Dello Russo et al. 2005), similar to gas rotational temperatures reported here for $17 \mathrm{P} /$ Holmes (Table 3 ). Therefore, assuming the relative intensities of the three detected $\mathrm{CH}_{3} \mathrm{OH}$ lines and the $\nu_{3} Q$-branch are the same in both comets, $g$-factors could be determined for the three $\mathrm{CH}_{3} \mathrm{OH}$ lines near $3000 \mathrm{~cm}^{-1}$ (Table 2; Fig. $3 c$ ) using the modeled $g$-factor of the $\mathrm{CH}_{3} \mathrm{OH} \nu_{3}$ $Q$-branch $\left(g=2.17 \times 10^{-5} \mathrm{~s}^{-1}\right.$; Bockelée-Morvan et al. 1995; Brooke et al. 2003; Dello Russo et al. 2007). On UT October 31.3, the $\nu_{3} Q$-branch was detected, and the production rate was determined in the usual manner.

Production rates measured in the coma of $17 \mathrm{P} /$ Holmes show enhanced relative production rates for $\mathrm{C}_{2} \mathrm{H}_{6}, \mathrm{C}_{2} \mathrm{H}_{2}, \mathrm{HCN}$, and perhaps $\mathrm{CH}_{3} \mathrm{OH}$ with respect to $\mathrm{H}_{2} \mathrm{O}$ when compared to other comets (Bockelée-Morvan et al. 2004). We note, however, that coma and nucleus ice abundances may be significantly different in $17 \mathrm{P}$ owing to the differences in volatilities for species measured, the large comet heliocentric distance, and the small aperture of our measurements. Furthermore, coma abundances in 17P may not be directly comparable to coma abundances determined in other comets because almost all detailed chemical information on parent volatiles in comets is obtained at small heliocentric distances, typically close to $1 \mathrm{AU}$. The most detailed information on parent volatile chemistry in comets at large heliocentric distances was obtained for $\mathrm{C} / 1995 \mathrm{O} 1$ (Hale-Bopp). Abundance ratios of $\mathrm{HCN} / \mathrm{OH}$ and $\mathrm{CH}_{3} \mathrm{OH} / \mathrm{OH}$ determined at radio wavelengths in Hale-Bopp were not significantly different between about 2.5 AU and perihelion (Biver et al. 1999). This suggests that the relative abundances of $\mathrm{HCN}$ and $\mathrm{CH}_{3} \mathrm{OH}$ with respect to $\mathrm{H}_{2} \mathrm{O}$ in $17 \mathrm{P}$ may be comparable to other comets if the heliocentric evolution of these volatiles in Hale-Bopp is typical. $\mathrm{C}_{2} \mathrm{H}_{2}$ and $\mathrm{C}_{2} \mathrm{H}_{6}$ are more volatile than $\mathrm{HCN}$ and $\mathrm{CH}_{3} \mathrm{OH}$, however, so their abundances with respect to $\mathrm{H}_{2} \mathrm{O}$ may be significantly different between 1 and 2.5 AU. Infrared observations measured $\mathrm{C}_{2} \mathrm{H}_{6}$ production rates out to 3.01 AU in Hale-Bopp (Dello Russo et al. 2001), but corresponding $\mathrm{H}_{2} \mathrm{O}$ measurements were not obtained beyond $1.49 \mathrm{AU}$ so a direct comparison with $17 \mathrm{P}$ at 2.45 AU is not possible.

Relative production rates in $17 \mathrm{P}$ are most similar to notably volatile-enhanced long-period comet C/2001 A2 (LINEAR) (Gibb et al. 2007; Magee-Sauer et al. 2008); however, observations of $\mathrm{C} / 2001 \mathrm{~A} 2$ were obtained at heliocentric distances between 1.16 and 1.59 AU so, as noted above, they may not be directly comparable. Relative production rates derived from the current study are in agreement with preliminary abundances derived from infrared measurements of $17 \mathrm{P}$ on UT October 29 and 30 with NIRSPEC (Salyk et al. 2007). The absolute $\mathrm{H}_{2} \mathrm{O}$ production rate derived on October $29\left(2.75 \times 10^{29}\right.$ molecules s ${ }^{-1}$; Salyk et al. 2007) falls between the values derived in this work on UT October 27.6 and 31.3 (Table 3) and is consistent with the rapid decline observed in our observations from October 27.6 to November 2.3.

Preliminary results obtained from larger aperture narrowband photometry on UT 2007 November 1 (the projected aperture radius ranged from $1.45 \times 10^{4} \mathrm{~km}$ to $1.202 \times 10^{5} \mathrm{~km}$ ) suggest a $\mathrm{H}_{2} \mathrm{O}$ production rate several times higher than reported in this work (Schleicher 2007). This may indicate that there was significant release of volatiles from icy grains outside our smaller aperture. Narrowband photometry results give relative production rates of $\mathrm{C}_{2} / \mathrm{OH} \sim 0.6 \%-0.7 \%$ and $\mathrm{CN} / \mathrm{OH} \sim 0.5 \%-0.6 \%$ (Schleicher 2007), which indicate an enhancement of $\mathrm{C}_{2}$ and $\mathrm{CN}$ relative to $\mathrm{OH}$ compared to other comets and $\mathrm{a}_{2} / \mathrm{CN}$ ratio consistent with a compositional classification of carbon-chain typical for 17P/Holmes (A'Hearn et al. 1995).

In this case the different aperture sizes used in the optical and infrared measurements may make relative abundance comparisons difficult; however, the high absolute $\mathrm{C}_{2}$ and $\mathrm{CN}$ production rates and high $\mathrm{C}_{2} / \mathrm{OH}$ and $\mathrm{CN} / \mathrm{OH}$ ratios indicate that in addition to $\mathrm{H}_{2} \mathrm{O}$ a significant amount of the more volatile parents of $\mathrm{C}_{2}$ and $\mathrm{CN}\left(\mathrm{C}_{2} \mathrm{H}_{2}, \mathrm{C}_{2} \mathrm{H}_{6}\right.$, and $\left.\mathrm{HCN}\right)$ were also released from icy grains outside our aperture. Because the evidence suggests that the release of volatiles from icy grains included all species and not any one species preferentially (i.e., that they are fairly representative of the nucleus ice composition), it is reasonable to assume that abundance ratios obtained from this work and that of Schleicher (2007) are comparable despite differences in aperture size. Assuming that relative abundances are comparable over the different aperture sizes, relative production rates from this work (Table 3) are consistent with $\mathrm{HCN}$ being the dominant source of $\mathrm{CN}$ in the coma of 17P; however, $\mathrm{C}_{2} \mathrm{H}_{2}$ can only account for about half of the total $\mathrm{C}_{2}$. Although $\mathrm{C}_{2} \mathrm{H}_{6}$ is not predicted to efficiently form $\mathrm{C}_{2}$ in the cometary coma (Helbert et al. 2005; Dello Russo et al. $2007)$, the large $\mathrm{C}_{2} \mathrm{H}_{6} / \mathrm{H}_{2} \mathrm{O}$ ratio in $17 \mathrm{P} /$ Holmes $(\sim 2 \%)$ suggests that a $\mathrm{C}_{2} \mathrm{H}_{6}$ to $\mathrm{C}_{2}$ conversion efficiency of about $10 \%-20 \%$ could account for the remaining $\mathrm{C}_{2}$.

\subsection{Spatial Distribution of Species in the Coma}

As discussed above, measured volatile abundances in the coma do not necessarily correspond to the composition of ices in the comet nucleus. This is true even for comets measured closer to $R_{h}=1$ AU because a volatile may sublime directly from ice in the nucleus (native source) or be released in the coma as a distributed source from grains, as a photodissociation product, or by active coma chemistry. A more complete understanding of the relationship between nuclear ices and coma gases can be obtained 

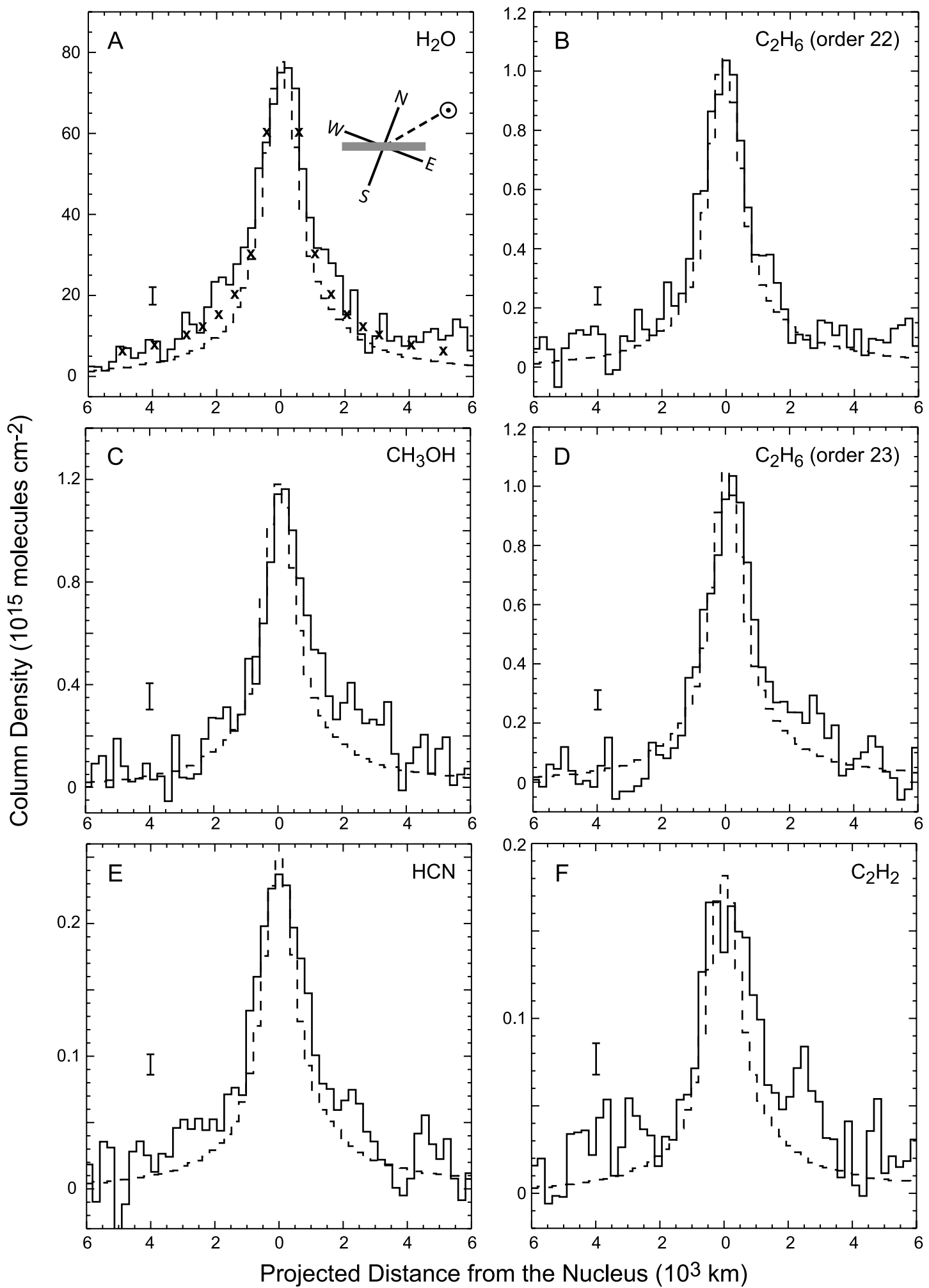

Fig. 5.- Spatial distribution of volatiles and the dust in 17P/Holmes on UT 2007 October 27.6. $(a) \mathrm{H}_{2} \mathrm{O}$ order $26 ;(b) \mathrm{C}_{2} \mathrm{H}_{6}$ order $22 ;(c) \mathrm{CH}_{3} \mathrm{OH}$ order $23 ;(d) \mathrm{C}_{2} \mathrm{H}_{6}$ order 23; $(e) \mathrm{HCN}$ order $25 ;(f) \mathrm{C}_{2} \mathrm{H}_{2}$ order 25 . Volatile column densities (solid lines) are compared to scaled dust column densities $\left(\right.$ dashed lines). A $\rho^{-1}$ distribution (crosses) scaled approximately to the gas emission and a compass indicating the direction of the Sun with respect to the comet are also shown in $(a)$. Plotted on the left side of each panel is the estimated $1 \sigma$ single pixel error bars based on deviations of spatial profiles from a fitted Gaussian + polynomial curve. The half-width at half-maximum of the spatial profiles from the fitted Gaussian + polynomial curves is about 3.5 pixels $(\sim 800 \mathrm{~km})$ and is consistent for all gas species and about 2.6 pixels $(\sim 600 \mathrm{~km})$ for dust in all orders. 
by measuring the spatial distributions (or spatial profiles) of species in the coma.

Neglecting outflow asymmetries, the column density of a volatile (or dust) sublimed directly from the nucleus only should fall off as $\rho^{-1}$, where $\rho$ is the projected distance from the nucleus, as long as the photodissociation scale length is much larger than $\rho$, which is the case for these observations of $17 \mathrm{P} /$ Holmes. The spatial profile for a species with a significant distributed source will be broader, falling off more slowly than $\rho^{-1}$ (Weaver et al. 1997; DiSanti et al. 2001; Brooke et al. 2003). However, outflow asymmetries, observing conditions, and optical depth effects can also affect profile shapes, causing deviations from a $\rho^{-1}$ distribution even for purely native species (Dello Russo et al. 2000; DiSanti et al. 2001). Comparison of spatial profiles for volatile species and dust (measured simultaneously) can provide a means for assessing the presence of a significant distributed source but are not reliable for identifying contributions from small distributed sources (DiSanti et al. 2001; Dello Russo et al. 2001; Brooke et al. 2003). Based on the volatile production rates and the spatial resolution of these measurements, optical depth effects are not important. Observations of comet $17 \mathrm{P} /$ Holmes were conducted at a comet heliocentric distance of $2.45 \mathrm{AU}$, and a comparison of absolute production rates derived from this work and narrowband photometry results (Schleicher 2007) suggest a distributed source of icy grains.

Emissions were sufficiently strong and numerous to measure the spatial distribution of all detected species in $17 \mathrm{P} /$ Holmes on October 27.6 (Fig. 5). In addition, these species were detected simultaneously within a single NIRSPEC setting, enabling a more direct comparison. Spatial profiles for all volatile species have similar spatial distributions to each other but are slightly broader than both the spatial distribution of dust in the coma and a $\rho^{-1}$ distribution (Fig. 5). Fitting a Gaussian plus polynomial curve to the gas and dust spatial profiles gives a half-width at halfmaximum of about 3.5 pixels $(\sim 800 \mathrm{~km})$ for all gas species and about 2.6 pixels $(\sim 600 \mathrm{~km})$ for dust in all orders (Fig. 5). We note that there are possibly significant asymmetries that appear for some species but not others (e.g., $\sim 2500 \mathrm{~km}$ east of the nucleus in Fig. 5) that may indicate short-term variability in the outgassing. However, the deviation from a $\rho^{-1}$ distribution is small, suggesting at most a minor contribution from sublimating icy grains within our aperture. The similar widths of the volatile spatial profiles also suggest that any icy grain sublimation is approximately uniform for all measured species, consistent with our inferences regarding icy grain composition obtained from the comparison of production rates derived from different aperture sizes (see previous section). We note that infrared spectral reflectance measurements with an aperture size similar to our measurements detected water ice grains in the coma (Yang \& Jewitt 2007). This supports the view that icy grains exist within our aperture but survive to greater coma distances and lead to significant sublimation of volatiles outside our aperture as suggested by the higher production rates derived from narrowband photometry observations (Schleicher 2007).

\section{SUMMARY}

The outburst of comet 17P/Holmes on UT October 23.8 (Hsieh et al. 2007) provided the opportunity to measure the chemical abundances in a Jupiter-family comet. Rotational temperatures of gases released in the coma were determined for four species on UT October 27.6 and were between 60 and $80 \mathrm{~K}$ ( Table 3), with small but significant differences seen between $\mathrm{HCN}$ and $\mathrm{C}_{2} \mathrm{H}_{6}$. Extension of fluorescence models for $\mathrm{C}_{2} \mathrm{H}_{6}$ and $\mathrm{C}_{2} \mathrm{H}_{2}$ enabled more stringent rotational temperatures and production rates to be determined by utilizing additional lines in the analysis (Figs. 3 and 4). In particular the use of $\nu_{5} \mathrm{C}_{2} \mathrm{H}_{6}$ lines enabled the determination of the best-constrained $\mathrm{C}_{2} \mathrm{H}_{6}$ rotational temperature in a comet to date (Fig. 3).

The overall volatile production rate of $17 \mathrm{P} /$ Holmes decreased by approximately a factor of 7 between UT October 27.6 and November 2.3 (Table 3 ). There is no evidence for heterogeneity within the nucleus of $17 \mathrm{P} / \mathrm{Holmes}$; however, only $\mathrm{H}_{2} \mathrm{O}$ and $\mathrm{C}_{2} \mathrm{H}_{6}$ were measured on all three dates (Table 3). Measured volatile abundances in $17 \mathrm{P} /$ Holmes (Table 3 , Figs. 1 and 2) show enhanced relative production rates for $\mathrm{C}_{2} \mathrm{H}_{6}, \mathrm{C}_{2} \mathrm{H}_{2}, \mathrm{HCN}$, and perhaps $\mathrm{CH}_{3} \mathrm{OH}$ with respect to $\mathrm{H}_{2} \mathrm{O}$ when compared to other comets (Bockelée-Morvan et al. 2004). We note that relative abundance comparisons to other comets should be interpreted cautiously owing to the range in volatilities of the species measured, the large comet heliocentric distance of these measurements (2.45 AU), and evidence of significant release of icy grains outside our aperture. However, the high absolute $\mathrm{C}_{2}$ and $\mathrm{CN}$ production rates and high $\mathrm{C}_{2} / \mathrm{OH}$ and $\mathrm{CN} / \mathrm{OH}$ ratios from narrowband photometry results and the similar spatial distributions of all measured volatiles within our aperture (Fig. 5) indicate that our results and those obtained with larger-aperture narrowband photometry may be comparable. Also, if the composition of icy grains released in the coma reflects that of the nucleus ices, the volatile abundances measured in this work may provide a valid comparison to other comets. Whether the enhancement of the more volatile ices was a factor that contributed to this large outburst is an open question.

Although the comet population shows a diversity of composition in general, there are perhaps some unexpected similarities in composition between comets from different dynamical families. The composition of $17 \mathrm{P} /$ Holmes most closely resembles that of long-period comet C/2001 A2 (LINEAR) (Gibb et al. 2007; Magee-Sauer et al. 2008). Similar compositions for comets from two different dynamical classes were also seen in volatile-depleted Jupiter-family comet 73P/Schwassmann-Wachmann 3 and longperiod C/1999 S4 (LINEAR) (Dello Russo et al. 2007; Mumma et al. 2001b). The range of measured composition within the comet population, coupled with the similar composition of some individual comets from different dynamical classes, reinforces that the relationships among formative region in the early solar nebula, evolutionary processing history, and measured comet chemistry are poorly understood at this time and that a larger statistical database of observations is needed.

The NASA Planetary Atmospheres and Planetary Astronomy Programs supported this work. Data were obtained at the NASA Infrared Telescope Facility operated by the University of Hawaii under Cooperative Agreement with the NASA Science Mission Directorate, Planetary Astronomy Program. Data were also obtained at the W. M. Keck Observatory, which is operated as a scientific partnership among the California Institute of Technology, the University of California, and the National Aeronautics and Space Administration. The Observatory was made possible by the generous financial support of the W. M. Keck Foundation. The authors also wish to acknowledge the significant cultural role and reverence that the summit of Mauna Kea has always had within the indigenous Hawaiian community. We are most fortunate to have the opportunity to conduct observations from this mountain.

Facilities: IRTF, Keck: II. 


\section{REFERENCES}

A'Hearn, M. F., Millis, R. L., Schleicher, D. G., Osip, D. J., \& Birch, P. V. 1995, Icarus, 118, 223

Belton, M. J. S., et al. 2007, Icarus, 187, 332

Biver, N., et al. 1999, Earth Moon Planets, 78, 5 2002, Earth Moon Planets, 90, 323

Bockelée-Morvan, D., Brooke, T. Y., \& Crovisier, J. 1995, Icarus, 116, 18

Bockelée-Morvan, D., Crovisier, J., Mumma, M. J., \& Weaver, H. A. 2004, in Comets II, ed. M. C. Festou, H. U. Keller, \& H. A. Weaver (Tucson: Univ. Arizona Press), 391

Bonev, B. P., Mumma, M. J., DiSanti, M. A., Dello Russo, N., Magee-Sauer, K., Ellis, R. S., \& Stark, D. P. 2006, ApJ, 653, 774

Bonev, B. P., et al. 2007, ApJ, 661, L97

Brooke, T. Y., Tokunaga, A. T., Weaver, H. A., Crovisier, J., Bockelée-Morvan, D., \& Crisp, D. 1996, Nature, 383, 606

Brooke, T. Y., et al. 2003, Icarus, 166, 167

Clough, S. A., Kneizys, F. X., Rothman, L. S., \& Gallery, W. O. 1981, SPIE, 277, 152

Clough, S. A., et al. 1988, in IRS'88: Current Problems in Atmospheric Radiation, ed. J. Lenoble \& J. F. Geleyn (Hampton: A. Deepak), 372

Crovisier, J. 1987, A\&AS, 68, 223 1994, J. Geophys. Res., 99, 3777

Dello Russo, N., Bonev, B. P., DiSanti, M. A., Mumma, M. J., Gibb, E. L., Magee-Sauer, K., Barber, R. J., \& Tennyson, J. 2005, ApJ, 621, 537

Dello Russo, N., DiSanti, M. A., Magee-Sauer, K., Gibb, E. L., Mumma, M. J., Barber, R. J., \& Tennyson, J. 2004, Icarus, 168, 186

Dello Russo, N., DiSanti, M. A., Mumma, M. J., Magee-Sauer, K., \& Rettig, T. W. 1998, Icarus, 135, 377

Dello Russo, N., Mumma, M. J., DiSanti, M. A., Magee-Sauer, K., Gibb, E. L., Bonev, B. P., McLean, I. S., \& Xu, L. H. 2006, Icarus, 184, 255

Dello Russo, N., Mumma, M. J., DiSanti, M. A., Magee-Sauer, K., \& Novak, R. 2001, Icarus, 153, 162
Dello Russo, N., Mumma, M. J., DiSanti, M. A., Magee-Sauer, K., Novak, R., \& Rettig, T. W. 2000, Icarus, 143, 324

Dello Russo, N., Vervack, R. J., Jr., Weaver, H. A., Biver, N., BockeléeMorvan, D., Crovisier, J., \& Lisse, C. M. 2007, Nature, 448, 172

DiSanti, M. A., Mumma, M. J., Dello Russo, N., Magee-Sauer, K., Novak, R., \& Rettig, T. W. 2001, Icarus, 153, 361

Gibb, E. L., et al. 2007, Icarus, 188, 224

Greene, T. P., Tokunaga, A. T., Toomey, D. W., \& Carr, J. B. 1993, Proc. SPIE, 1946, 313

Helbert, J., Rauer, H., Boice, D. C., \& Huebner, W. F. 2005, A\&A, 442, 1107 Hsieh, H. H., Fitzsimmons, A., \& Pollacco, D. L. 2007, IAU Circ. 8897

Magee-Sauer, K., Mumma, M. J., DiSanti, M. A., \& Dello Russo, N. 2002, J. Geophys. Res., 107, 5096, DOI: 10.1029/2002JE001863

Magee-Sauer, K., Mumma, M. J., DiSanti, M. A., Dello Russo, N, \& Rettig, T. W. 1999, Icarus, 142, 498

Magee-Sauer, K., et al. 2008, Icarus, 194, 347

McLean, I. S., et al. 1998, Proc. SPIE, 3354, 566

Mumma, M. J., et al. 2001a, ApJ, 546, 1183 2001b, Science, 292, 1334

Roberts, I. 1892, MNRAS, 53, 65

Rothman, L. S., et al. 2005, J. Quant. Spectrosc. Radiat. Transfer, 96, 139 Salyk, C., et al. 2007, IAU Circ. 8890

Santana, J. A. H. 2007, IAU Circ. 8886

Schleicher, D. 2007, IAU Circ. 8889

Sekanina, Z. 2007, Central Bureau Electron. Tel., 1118

Thomas, P. C., et al. 2007, Icarus, 187, 4

Weaver, H. A., et al. 1997, Earth Moon Planets, 78, 71

Whipple, F. L. 1984, Icarus, 60, 522 1999, Planet. Space Sci., 47, 301

Xie, X., \& Mumma, M. J. 1992, ApJ, 386, 720

Yang, B., \& Jewitt, D. 2007, IAU Circ. 8892 